\title{
Pulmonary function in children with systemic lupus erythematosus
}

\author{
I Cerveri, F Fanfulla, A Ravelli, M C Zoia, B Ramenghi, L Spagnolatti, I Villa, \\ A Martini
}

\begin{abstract}
Background - Abnormalities of pulmonary function have been found in children with systemic lupus erythematosus (SLE) even in the absence of clinical or radiographic evidence of pulmonary involvement. It is unknown whether these abnormalities represent an early sign of progressive lung disease or whether they are associated with disease activity.
\end{abstract}

Methods - After a mean of 4.5 years, respiratory function (forced vital capacity (FVC) and single breath gas transfer factor (TLCO)) and disease activity were reexamined in 13 of 15 previously studied children with SLE. Disease activity was assessed by a validated index of SLE activity (SLE activity measure (SLAM)).

Results - In spite of the high prevalence of abnormalities of respiratory function at the baseline investigation, no chest radiographic abnormalities or overt clinical signs of lung disease were found at baseline, in the interval between the two investigations, or at the re-evaluation in any patient. From baseline to the second investigation the mean value of SLAM decreased and there was a trend toward an improvement in FVC and TLCO. TLCO was more severely impaired than FVC, being found as an isolated abnormality in a high percentage of patients $(45 \%$ at baseline and $35 \%$ at follow up). There was a relationship between baseline TLCo and disease activity, expressed as a SLAM score. Moreover, there was a correlation between the changes in the SLAM score from baseline to the second investigation and the corresponding changes in the TLCo value, but not with the corresponding changes in the FVC value.

Conclusions - In this series of patients the decrease in SLE activity from the first to the second investigation was associated with an improvement in pulmonary function. The presence of early isolated functional abnormalities was not associated with subsequent development of lung disease.

(Thorax 1996;51:424-428)

Keywords: systemic lupus erythematosus, pulmonary function tests.

Abnormalities of pulmonary function are a frequent finding in children with connective tissue diseases. ${ }^{1-8}$ However, it is not known whether they represent an early sign of progressive lung disease which is not clinically evident, or simply reflect non-progressive, potentially reversible, pulmonary damage. Little is known about the impact of fluctuations of the systemic inflammatory process or the effect of therapy on functional impairment. Indeed, most of the available data on pulmonary function in childhood connective tissue diseases have been obtained by cross sectional investigations whereas longitudinal studies are scarce.

We have previously found, in a cross sectional study, a high prevalence of functional abnormalities of the lung in children with clinically active connective tissue diseases, but not in those in remission. ${ }^{9}$ None of these patients had clinical or radiographic evidence of pulmonary involvement.

With the aim of investigating the long term evolution of pulmonary function and its relationship with changes in disease activity as assessed by standard methods, a group of children with systemic lupus erythematosus (SLE) previously studied was re-evaluated at least three years after a first evaluation.

\section{Methods}

\section{STUDY DESIGN}

Of 15 children with SLE included in the baseline investigation, ${ }^{10}$ two were lost from the second investigation. The remaining 13 patients (12 girls; age range 12-21 years) were re-evaluated after a mean of 4.5 years. Assessments of the disease activity, pulmonary function tests, oxygen saturation, and chest radiographic appearances were performed at baseline and at re-evaluation.

In the interval between the two investigations all the children had routine clinical examinations in the paediatric department every 3-6 months or more frequently if indicated. Pulmonary function tests and/or chest radiographs were also requested whenever clinically indicated.

\section{PATIENTS}

The main demographic and clinical data of the 13 patients are summarised in table 1 . The duration of the disease at the time of the baseline investigation ranged from one to 57 months. None of the children had a past history of pleural or pulmonary involvement. All the children were receiving drug treatment, whose dosage and regimen were adapted at each visit according to the severity and activity of the disease. All patients received prednisone, six were taking azathioprine, four cyclo- 
Table 1 Demographic and clinical features of patients

\begin{tabular}{llllll}
\hline $\begin{array}{l}\text { Patient } \\
\text { no. }\end{array}$ & $\begin{array}{l}\text { Age } \\
\text { (years) }\end{array}$ & Sex & $\begin{array}{l}\text { Disease } \\
\text { duration } \\
\text { (months)* }\end{array}$ & $\begin{array}{l}\text { Time } \\
\text { interval } \\
\text { (months)** }\end{array}$ & $\begin{array}{l}\text { Drug } \\
\text { therapy** }\end{array}$ \\
\hline 1 & $12 \cdot 7$ & F & 52 & 44 & PDN,CFM, \\
2 & $16 \cdot 1$ & F & 45 & 70 & AZA,HCQ \\
3 & $12 \cdot 7$ & $\mathrm{~F}$ & 2 & 48 & PDN,AZA \\
4 & $10 \cdot 6$ & $\mathrm{~F}$ & 19 & 35 & PDN,AZA \\
5 & $14 \cdot 1$ & $\mathrm{~F}$ & 27 & 53 & PDN \\
6 & $7 \cdot 1$ & $\mathrm{~F}$ & 2 & 50 & PDN,AZA \\
7 & $14 \cdot 9$ & $\mathrm{M}$ & 14 & 55 & PDN,CFM \\
8 & $10 \cdot 4$ & $\mathrm{~F}$ & 46 & 59 & PDN,CFM,AZA \\
9 & $16 \cdot 3$ & $\mathrm{~F}$ & 54 & 67 & PDN \\
10 & $13 \cdot 8$ & $\mathrm{~F}$ & 17 & 44 & PDN \\
11 & $14 \cdot 1$ & $\mathrm{~F}$ & 1 & 46 & PDN,CFM,AZA \\
12 & $18 \cdot 2$ & $\mathrm{~F}$ & 30 & 66 & PDN \\
13 & $10 \cdot 2$ & $\mathrm{~F}$ & 57 & 69 & PDN \\
\hline
\end{tabular}

$\mathrm{PDN}=$ prednisone $\mathrm{CFM}=$ cyclophosphamide; $\mathrm{AZA}=$ azathioprine $\mathrm{HCQ}=$ hydroxychloroquine . * At the time of the baseline evaluation.

** Between the baseline and the second investigation

phosphamide, and one hydroxychloroquine. None of the patients who took cyclophosphamide had any short term adverse effects from it.

\section{ASSESSMENT OF DISEASE ACTIVITY}

The SLE activity was assessed and scored by means of the SLE activity measure (SLAM), ${ }^{11}$ as previously reported. ${ }^{12}$ The SLAM is a validated system which allows a quantitative assessment of overall SLE activity, and covers symptoms during the previous month including 24 clinical manifestations and eight laboratory parameters. The items chosen represent those manifestations that occur more frequently, those that can be graded, and those that can be reliably rated. Since disease activity is always considered with disease severity, both dimensions are incorporated in the scale. A manifestation or symptom is determined as being either active or not active. Severity is then used to expand the scale from 1 to 3 and is judged by the need to treat with immunosuppressive agents, the need to follow the patient more closely, or the functional or prognostic consequences of the manifestation. The maximum score is 86 .

\section{PULMONARY FUNCTION TESTS}

Measurement of lung volumes were carried out using a water sealed spirometer and a helium analyser (Jaeger, Wuerzburg, Germany): the best of three forced vital capacity (FVC) meas-

Table 2 Individual data of SLAM, FVC, and TLCO at baseline and at re-evaluation

\begin{tabular}{|c|c|c|c|c|c|c|}
\hline $\begin{array}{l}\text { Patient } \\
\text { no. }\end{array}$ & $\begin{array}{l}\text { Baseline } \\
\text { SLAM }\end{array}$ & $\begin{array}{l}\text { Repeat } \\
\text { SLAM }\end{array}$ & $\begin{array}{l}\text { Baseline } \\
\text { FVC } \\
\text { (l) }\end{array}$ & $\begin{array}{l}\text { Repeat } \\
F V C \\
\text { (I) }\end{array}$ & $\begin{array}{l}\text { Baseline } \\
\text { TLCO } \\
\text { (kPa/s) }\end{array}$ & $\begin{array}{l}\text { Repeat } \\
\text { TLCO } \\
(k P a / s)\end{array}$ \\
\hline 1 & 10 & 6 & -1.789 & $-2 \cdot 5$ & -3.49 & $-2 \cdot 33$ \\
\hline 2 & 2 & 2 & -1.068 & -1.58 & $-3 \cdot 75$ & $-3 \cdot 58$ \\
\hline 3 & 0 & 0 & 0.045 & 0.66 & $-1 \cdot 64$ & 0.95 \\
\hline 4 & 6 & 6 & -1.63 & 0.09 & & \\
\hline 5 & 4 & 2 & -0.38 & 1.04 & $-0 \cdot 22$ & -0.64 \\
\hline 6 & 18 & 0 & -0.38 & $1 \cdot 853$ & $-4 \cdot 08$ & 0.9 \\
\hline 7 & 0 & 0 & -0.96 & -0.44 & 0.02 & -0.09 \\
\hline 8 & 1 & 1 & $0 \cdot 26$ & $1 \cdot 44$ & & \\
\hline 9 & 5 & 3 & $-1 \cdot 87$ & -1.83 & -0.99 & -1.92 \\
\hline 10 & 4 & 0 & $-3 \cdot 13$ & -0.4 & $-3 \cdot 24$ & $0 \cdot 7$ \\
\hline 11 & 16 & 3 & 0.99 & $1 \cdot 02$ & $-3 \cdot 27$ & $-2 \cdot 15$ \\
\hline 12 & 0 & 0 & 0.44 & $0 \cdot 38$ & 0.06 & -2.33 \\
\hline 13 & 3 & 0 & $-1 \cdot 4$ & $-1 \cdot 38$ & -1.96 & -1.96 \\
\hline
\end{tabular}

SLAM $=$ SLE activity measure; FVC $=$ forced vital capacity; TLCO = carbon monoxide transfer factor. urements were registered. The transfer factor of the lung for carbon monoxide (TLCO) was determined using the single breath method (Transferscreen-II Jaeger, Wuerzburg, Germany) and corrected for haemoglobin content. Since the correction of TLCo for alveolar volume did not influence the results of our analysis, only uncorrected TLCO values were reported. TLCO measurement was unreliable in two patients. Oxygen saturation was measured by means of a pulse oximeter (Oxy Shuttle, Sensor Medics, California, USA). All the respiratory function tests were performed according to the European Community for Coal and Steel statement. ${ }^{13}$ Since in our previous work the most informative variables were found to be FVC and TLCO, ${ }^{9}$ only these parameters were included in the analysis.

Changes in FVC and TLCo between the first and second investigation were considered significant when they exceeded the normal variability of the test itself $(>15 \%$ for FVC; $>10 \%$ for TLCO). ${ }^{13}$

A cross sectional study on lung function in healthy schoolchildren aged $4 \cdot 6-18 \cdot 8$ years has recently been performed and reference standards throughout childhood and puberty are now available. ${ }^{1415} \mathrm{We}$ employed these reference equations and, in accordance with the ECCS statement, ${ }^{13}$ we expressed the data from our subjects as a standard deviation (SD) score (actual result - predicted results/population standard deviation) and defined it as pathological when the value was less than $-1 \cdot 64$, corresponding to less than the fifth percentile. Taking into account the pubertal stage of each subject at each respiratory function assessment, the SD score was corrected according to the tables reported by Rosenthal et al. ${ }^{1415}$ Pubertal stage was evaluated according to Tanner's method. ${ }^{16}$

\section{STATISTICAL ANALYSIS}

The comparison between the mean baseline and control values of respiratory functional data and the disease activity measure was performed by a paired $t$ test. Simple linear regression analysis was employed to evaluate the correlation between baseline FVC, TLCO, and baseline SLAM, and between the changes in the FVC and TLCo along with changes in the SLAM from the first to the second investigation. Changes in the functional parameters were determined as the difference $(\Delta)$ between each control and baseline SD score and changes in disease activity as the difference $(\Delta)$ between each control and baseline SLAM score.

\section{Results}

No overt clinical signs of lung disease or chest radiographic abnormalities were found at baseline, in the interval between the two investigations, or at re-evaluation in any patient, including those with the most severe abnormalities in lung function tests.

Table 2 reports the individual values of SLAM, FVC, and TLCo for each child at base- 
Table 3 Mean (SD) values of SLAM, FVC, TLCO, and percentage of patients with negative SD score and with clearly pathological score $(<-1 \cdot 64)$ at baseline and at re-evaluation

\begin{tabular}{lllllll}
\hline & $\begin{array}{l}\text { No. of } \\
\text { patients }\end{array}$ & $\begin{array}{l}\text { SLAM } \\
\text { score }\end{array}$ & $\begin{array}{l}\text { FVC } \\
\text { (SD score) }\end{array}$ & $\begin{array}{l}\text { TLCO } \\
\text { (SD score) }\end{array}$ & $\begin{array}{l}\text { \% of patients } \\
\text { with negative } \\
\text { SD score }\end{array}$ & $\begin{array}{l}\text { \% of patients } \\
\text { with SD score } \\
<-1.64\end{array}$ \\
\hline $\begin{array}{lllll}\text { Baseline } \\
\text { Repeat }\end{array}$ & 13 & $5.38(5.92)^{*}$ & $-0.74(1.23)$ & & 61 & 31 \\
& 13 & $1.77(2.2)^{*}$ & $-0.12(1.36)$ & & 53 & 23 \\
Baseline & 11 & $5.64(6.33)^{*}$ & & $-2.05(1.59)$ & 81 & 64 \\
Repeat & 11 & $1.45(1.97)^{*}$ & & $-1.17(1.59)$ & 72 & 54.5 \\
\hline
\end{tabular}

${ }^{*} \mathrm{p}<0.05$.

line and at the second assessment. Table 3 shows the mean (SD) baseline and repeat values for SLAM, FVC, and TLCO, and the percentage of subjects with a negative SD score and with a clearly pathological SD score $(<-1 \cdot 64)$. The mean SLAM score decreased significantly between baseline and re-evaluation $(p<0.05)$. The mean values of FVC and TLco were negative both at baseline and at repeat measurement. Although the difference was not statistically significant, there was a trend towards an improvement in both respiratory parameters from the first to the second investigation. The percentage of patients with a negative SD score and clearly pathological respiratory function was slightly reduced at reevaluation. TLCO was more severely impaired than FVC both at baseline and at the second examination, being found as an isolated abnormality in a high percentage of patients (45\% at baseline and $35 \%$ at control).

At baseline only TLCo was significantly correlated with SLAM $(r=0.65, \mathrm{p}<0.05)$ (fig 1). From baseline to the second investigation the SLAM score improved in seven subjects, was unchanged in four, and worsened in two. The FVC value improved in seven subjects, was unchanged in four, and worsened in two (fig 2 ). The TLco value improved in five subjects, remained unchanged in three, and worsened in three (fig 3). The changes in the TLco value from baseline to re-evaluation were significantly correlated with the corresponding changes in the SLAM scores $(r=0.62, \mathrm{p}<0.05)$ (fig 4$)$, while the changes in the FVC were not. Of note, the three patients who showed the more impressive improvement in TLCO at re-

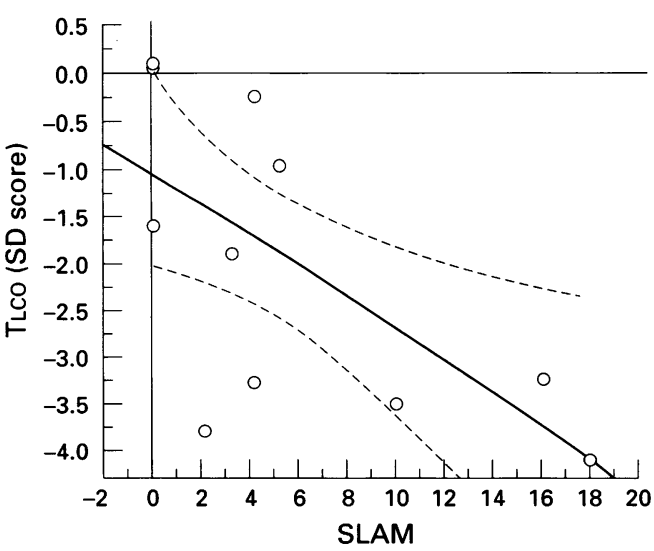

Figure 1 Correlation between baseline carbon monoxide transfer factor (TLCO) expressed as an SD score and SLE activity measure (SLAM); - = regression line; - - =90\% confidence intervals. evaluation (from severely abnormal to normal values) concurrently achieved a clinical remission.

Oxygen saturation was normal $(>95 \%)$ in all the patients, even in the most compromised, both at baseline and at re-evaluation.

\section{Discussion}

Our study in 13 children with SLE shows that functional lung impairment is related to the activity of the systemic inflammatory process. This finding is in agreement with the results of our previous cross sectional investigation. ${ }^{9}$ Indeed, we found a relationship between TLCO impairment and the activity of the disease expressed as a SLAM score. Moreover, from the first to the second assessment we observed a significant correlation between lessening of disease activity and improvement of TLCO. As in adult onset SLE, TLCO was more severely impaired than FVC. ${ }^{17} \mathrm{~A}$ low FVC may be due to either respiratory muscle function impairment or to interstitial lung disease, ${ }^{61718}$ but the finding of a proportionately lower TLCO than FVC suggests that there is a pulmonary parenchymal defect rather than respiratory

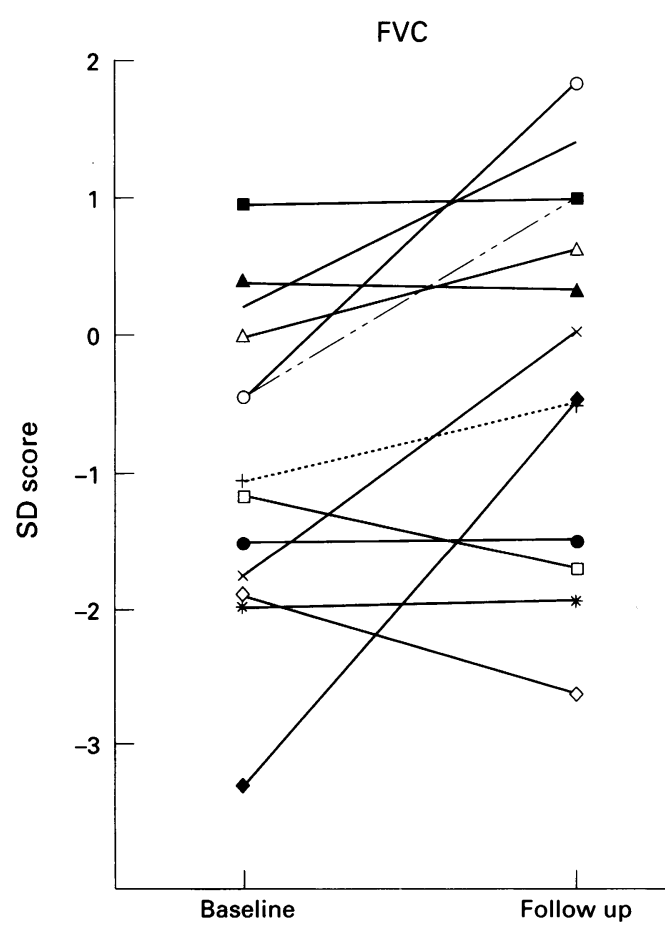

Figure 2 Baseline and repeat values of forced vital capacity (FVC) expressed as an SD score for each subject (each symbol corresponds to a patient number in table 1). 


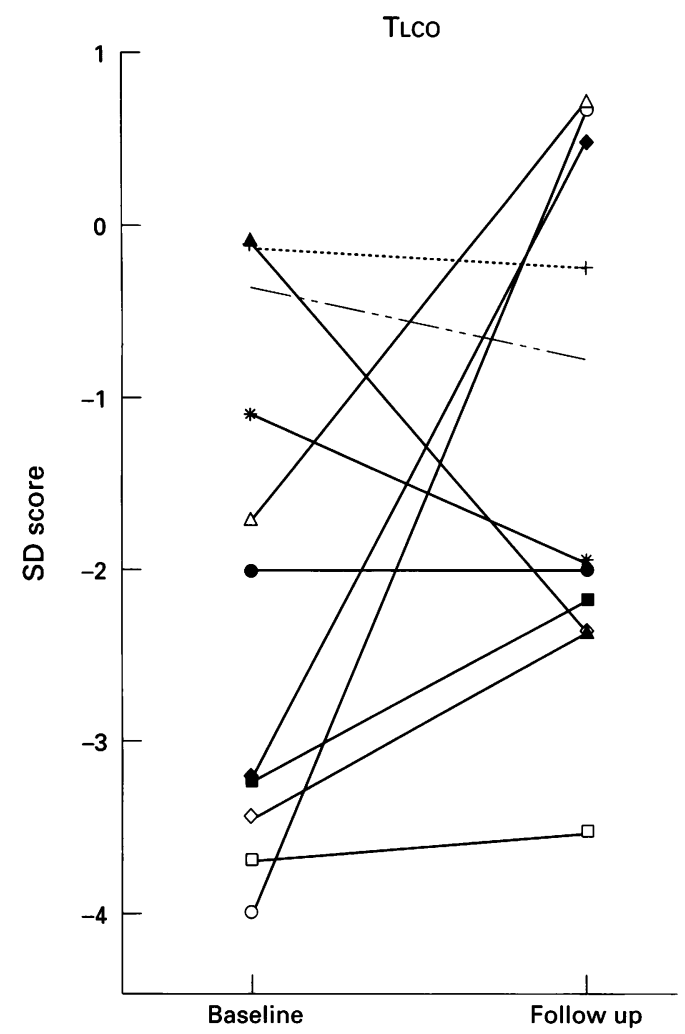

Figure 3 Baseline and repeat values of carbon monoxide transfer factor (TLCO) expressed as an SD score for each subject (each symbol corresponds to the same patient as in fig 2).

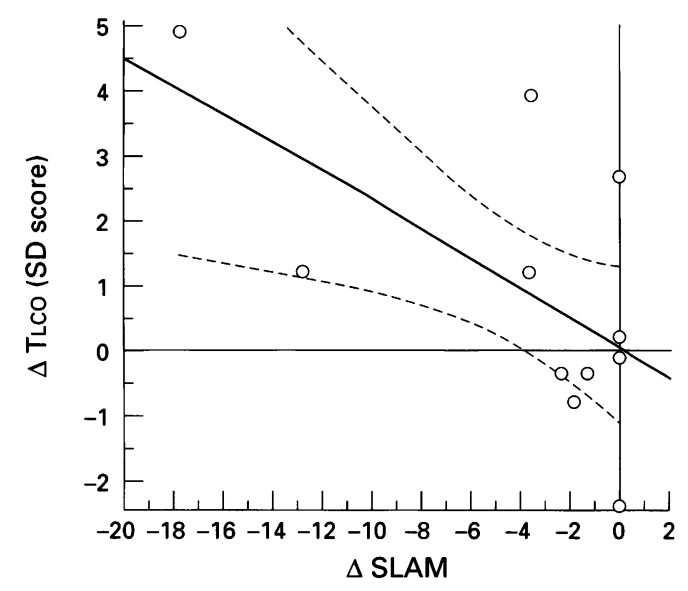

Figure 4 Correlation between the changes in carbon monoxide transfer factor ( $\triangle T L C O$ ) expressed as an $S D$ score and the changes in SLE activity measure ( $S S L A M) ;-=$ regression line; -- =90\% confidence intervals.

muscle impairment in our patients. In contrast, De Jongste $e t a l^{6}$ suggested that impairment of respiratory muscle strength due to myopathy had a role in the impairment of lung function in their patients; however, their subjects were children with chest radiographic abnormalities and, in particular, diaphragm elevation and clinical and electromyographic signs of myopathy in other muscles. Unfortunately, data on maximal respiratory mouth pressures were not reproducible enough in our children and were thus not analysed; TLCo proved to be more sensitive in detecting the degree of lung involvement, as has also been shown in adult onset SLE. ${ }^{17}$ Only TLCo was found to be correlated with the disease activity measure and with its changes during the study period. Nailfold capillary morphological changes are associated with impairment of lung function, especially with the pulmonary transfer factor, and it has been suggested that microvascular changes can contribute to the development of interstitial lung disease. ${ }^{1920}$ Whether this also applies in children with SLE is not known.

Despite the high prevalence of abnormalities of respiratory function, none of our patients developed overt clinical or radiographic signs of lung involvement between the first and the second investigation, suggesting that abnormalities of respiratory function alone should not be regarded as an early sign of progressive lung disease.

There are few studies on pulmonary function in children with SLE because the disease is uncommon. ${ }^{4-7}$ No long term studies on children with SLE are available apart from some patients studied serially in two cross sectional studies. ${ }^{67}$ Singsen and Platzker found a restrictive defect in seven, ${ }^{4}$ an obstructive defect in one, and diffusion impairment in five of 20 children with SLE without clinical or radiographic evidence of pulmonary disease. Weiss et $a l^{5}$ reported a high frequency of abnormal pulmonary function in 28 children with SLE studied regardless of the presence or absence of pulmonary symptoms. Seventeen patients had a restrictive pattern, with an obstructive pattern in only one case. A diffusion defect was observed in about one third of patients. All but one of the eight patients studied by De Jongste et $a l^{6}$ had chest radiographic abnormalities at the time of the investigations and three had presented with pulmonary symptoms. Spirometric data obtained in seven patients showed severe restriction in four. In all six subjects in whom it was measured, TLCO was decreased for body surface area but normal or increased for total lung capacity. Repeated lung function measurements at six month intervals in four patients showed a gradual improvement in vital capacity in three patients which was unaffected by changes in the activity of SLE. Delgado $e t$ $a l^{7}$ studied 13 children with SLE irrespective of the presence or absence of clinical or radiographic lung disease. Eight patients (62\%) showed one or more defects: decreased lung diffusion was the commonest defect occurring in $67 \%$ of the patients studied, whereas restrictive and obstructive changes were observed in $46 \%$ and $8 \%$ of patients, respectively. In one of the five patients who had serial studies, abnormal function returned to normal.

Compared with previous investigations, our investigation provides an improvement in the definition of respiratory function status. We used new reference standards for spirometric values and single breath analysis and expressed the results as SD scores, as recommended by the ECCS. ${ }^{13-15}$ This is an accurate method which, taking into account the dispersion of the parameter in the reference population, allows a precise definition of the pathological subjects. The comparison of functional respiratory data between subjects with chronic diseases and 
their healthy counterparts is generally from normal values obtained from a reference equation including only age and height. However, it is known that chronic inflammatory diseases such as SLE can affect somatic growth either directly or because of long term treatment with drugs such as corticosteroids. ${ }^{21}$ To avoid this bias, which is particularly relevant for longitudinal data, we calculated the SD score with pubertal correction factors by using the new regression equations. Since puberty has a dramatic effect on lung function, ${ }^{14}{ }^{15}$ we could evaluate lung abnormalities more specifically.

1 Singsen $\mathrm{BH}$, Bernstein $\mathrm{BH}$, Korneich $\mathrm{HK}$, King $\mathrm{KK}$, Hanson V. Mixed connective tissue disease in childhood. F Pediatr 1977;90:893-900.

2 Oetgen WJ, Boice JA, Lawless OJ. Mixed connective tissue disease in children and adolescents. Pediatrics 1981;67: 333-7.

3 Wagener JS, Taussig LM, De Benedetti C, Lemen RJ, Loughlin GN. Pulmonary function in juvenile rheumatoid arthritis. F Pediatr 1984; 105:947-50.

4 Singsen BH, Platzker CG. Pulmonary involvement in the heumatic disorders of children. In: Kendig EL, Chernick V, eds Disorders of the respiratory tract in children. 4 th edn Philadelphia: WB Saunders, 1983:846-72

5 Weiss SG, Wagner-Weiner L, Newcomb RW. Assessment of pulmonary function in childhood systemic lupus erythematosus. Arthritis Rheum 1984;27:S63.

6 De Jongste JC, Neijens HJ, Duiverman EJ, Bogaard JM, Kerrebijn KF. Respiratory tract disease in systemic lupus erythematosus. Arch Dis Child 1986;61:478-83.

7 Delgado EA, Malleson PN, Pirie GE, Petty RE. The pulmonary manifestations of childhood onset systemic lupus monary manifestations of childhood onset systemic lupus

8 Garthy BZ, Athreya BH, Wilmott R, Scarpa N, Doughty $R$, Douglas SD. Pulmonary functions in children with progressive systemic sclerosis. Pediatrics 1991;88:1161-7.
9 Cerveri I, Bruschi C, Ravelli A, Zoia MC, Fanfulla F, Zonta $\mathrm{L}$, et al. Pulmonary function in childhood connective tissue diseases. Eur Respir f 1992;5:733-8.

10 Tan EM. Curen AS, Fries JF, Masi AT, McShane DJ, Rothfield NF, et al. The 1982 revised criteria for the Rothfield NF, et al. The 1982 revised criteria for the
classification of systemic lupus erythematosus. Arthritis classification of systemic
Rheum 1982;25:1271-7.

11 Liang MH, Socher SA, Larson MG, Schur PH. Reliability and validity of six systems for the clinical assessment of disease activity in systemic lupus erythematosus. Arthritis Rheum 1989;32:1107-18.

12 Ravelli A, Caporali R, Di Fuccia G, Zonta L, Montecucco C, Martini A. Anticardiolipin antibodies in pediatric systemic lupus erythematosus. Arch Pediatr Adolesc Med 1994:148. 398-402.

13 ESCC. Report of Working Party on standardization of lung function tests. Eur Respir F 1993;6:S16.

14 Rosenthal M, Bain SH, Cramer D, Helms P, Denison D, Bush A, et al. Lung function in white children aged 4 to 19 years: I - Spirometry. Thorax 1993;48:794-802.

15 Rosenthal M, Cramer D, Bain SH, Denison D, Bush A, Warner JO. Lung function in white children aged 4 to 19 years: II - Single breath analysis and plethysmography. Thorax 1993;48:803-8.

16 Tanner JM. Growth at adolescence. 2nd edn. Oxford: Blackwell, 1962

17 Andonopoulos AP, Costantopoulos SH, Galanopoulou V, Drosos AA, Acritidis NC, Moutsopoulos HM. Pulmonary function in non-smoking patients with systemic lupus function in non-smoking patients with
erythematosus. Chest 1992;92:312-5.

18 Elkayam O, Segal R, Caspi D, Yaron M, Greif Y. Restrictive lung disease due to diaphragmatic dysfunction in systemic lupus erythematosus. Two case reports. Clin Exp Rheumatol 1992;10:267-9.

19 Groen H, TerBorg EJ, Postma DS, Wouda AA, Van Der Mark TW, Kallenberg CGM. Pulmonary function in systemic lupus erythematosus is related to distinct clinical, serological, and nailfold capillary patterns. $A m f \mathcal{M e d}$ 1992;93:619-27.

20 Pallis M, Hopkinson N, Powell R. Nailfold capillary density as a possible indicator of pulmonary capillary loss in as a possible indicator of pulmonary capillary loss in systemic lupus erythematosus but not in mixed

21 Jacobs JC. Pediatric rheumatology for the practitioner. 2nd edn. New York: Springer-Verlag, 1993:409-526. 